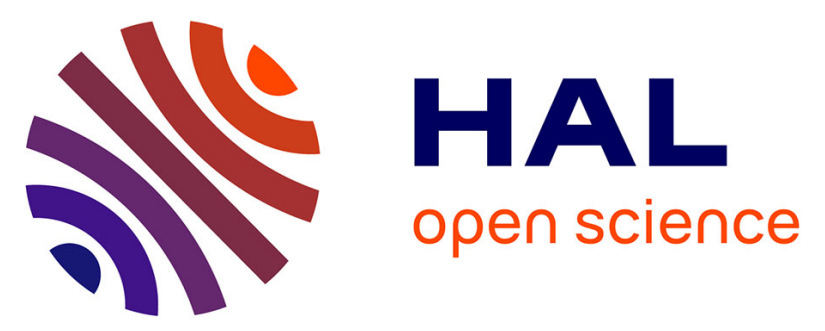

\title{
Programmable Orbital Angular Momentum beam generated from a 61 channels Coherent Beam Combining femtosecond laser
}

Jean-Christophe Chanteloup, Matthieu Veinhard, Séverine Bellanger, Louis Daniault, Ihsan Fsaifes

\section{To cite this version:}

Jean-Christophe Chanteloup, Matthieu Veinhard, Séverine Bellanger, Louis Daniault, Ihsan Fsaifes. Programmable Orbital Angular Momentum beam generated from a 61 channels Coherent Beam Combining femtosecond laser. Conference on Lasers and Electro-Optics (CLEO), May 2020, san francisco, United States. 10.1364/CLEO_SI.2020.STh4P.3 . hal-02995244

\section{HAL Id: hal-02995244 \\ https://hal.science/hal-02995244}

Submitted on 19 Nov 2020

HAL is a multi-disciplinary open access archive for the deposit and dissemination of scientific research documents, whether they are published or not. The documents may come from teaching and research institutions in France or abroad, or from public or private research centers.
L'archive ouverte pluridisciplinaire HAL, est destinée au dépôt et à la diffusion de documents scientifiques de niveau recherche, publiés ou non, émanant des établissements d'enseignement et de recherche français ou étrangers, des laboratoires publics ou privés. 


\title{
Programmable Orbital Angular Momentum beam generated from a 61 channels Coherent Beam Combining femtosecond laser
}

\author{
Matthieu Veinhard $^{* 1}$, Séverine Bellanger ${ }^{1}$, Louis Daniault ${ }^{1,2}$, Ihsan Fsaifes ${ }^{1}$, \\ and Jean-Christophe Chanteloup ${ }^{1}$ \\ ${ }^{1}$ XCAN, Ecole Polytechnique, Institut Polytechnique de Paris, 91128 Palaiseau cedex, France \\ ${ }^{2}$ LOA, ENSTA, Institut Polytechnique de Paris, 91120 Palaiseau \\ *matthieu.veinhard@polytechnique.fr
}

\begin{abstract}
A 61 beamlets Coherent Beam Combination laser is used as a programmable phase source to generate high power Orbital Angular Momentum beams and open the path for higher order nonsymmetrical user-defined far field distributions. (C) 2020 The Author(s)
\end{abstract}

Application fields of Orbital Angular Momentum (OAM) laser beams keeps extending, ranging from selective trapping of particles [1], microbunching instability reduction in free-electron laser setups [2] to fluids flow characterization [3]. Traditional methods to generate such beams generally rely on laser cavity tuning [4] or SpatialLight Modulators (SLMs) [5]. The first one offers high output powers but lacks of tunability, as a different cavity design must be engineered for each specific transverse beam distribution. The second method offers high tunability but is limited in output power by the SLM optical damage threshold. A more versatile alternative approach, potentially offering both high output power and tunability, is based on Coherent Beam Combination (CBC) of numerous beamlines [6]. We demonstrate the generation of AOM beams with the XCAN CBC prototype [7] where an array of 61 honeycomb distributed fibers allows a high-resolution phase control (figure 1).

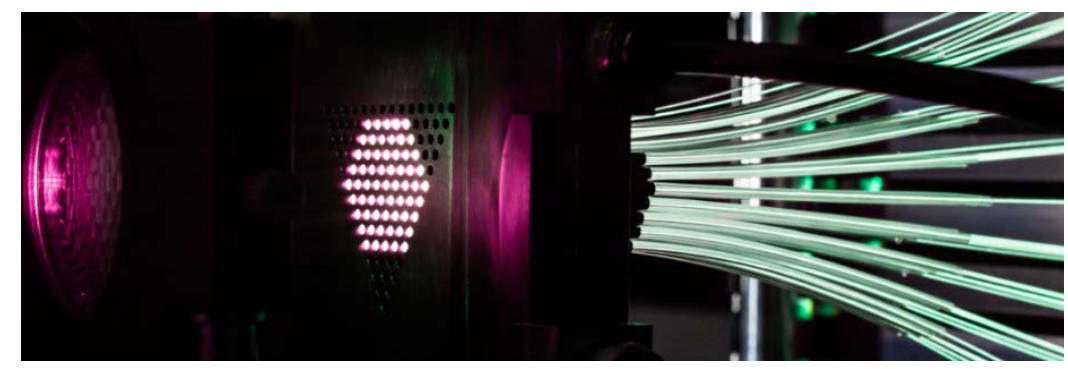

Fig. 1. XCAN laser head (center), collimating microlens array (left) and 61 Yb:doped fiber bundle (right).

This laser carries a high potential for greatly broadening the field of applications of structured light far beyond AOM centrosymmetric beams only. It indeed associates high peak (fs regime operation) and average (kW range) powers thanks to its diode-pumped Yb-doped fiber amplifying chain architecture. Scalable by nature, it has been studied to be compatible with up to 10,000 channels [8] paving the way to high resolution transverse amplitude and phase laser beam control. Hundreds to thousands of control points within the pupil would allow arbitrary shaped phase and amplitude distribution (not limited to cylindrical symmetries like for AOM) to be implemented through iterative electric field computing with Gerchberg-Saxton algorithm [9] for instance. Finally, this electric field control can be adjusted in real time (up to the $\mathrm{kHz}$ regime at the moment) offering an extra degree of freedom for applications requesting dynamic energy or power distribution control (drilling, cutting or soldering of material for instance).

The XCAN laser setup $[7,10]$ relies on 61 individually amplified and coherently combined beamlets, the phase of each being controlled in real time $(\mathrm{kHz})$ via the combined used of variable optical delay lines, piezo-mechanical fiber stretchers, an interferometric phase measurement and a Stochastic Parallel Gradient Descent (SPGD) algorithm. Individual amplitudes can be adjusted through amplifier gain control.

The XCAN laser is then used to generate "61 pixels" $I^{\text {th }}$-order OAM beams phases expressed as:

$\varphi(x, y)=l \cdot \tan ^{-1}\left[\left(y-y_{0}\right) /\left(x-x_{0}\right)\right]$, where $l \in \mathbb{Z}$ is the topological charge number, $(x, y)$ the beamlets position relative to the central beamlet position $\left(x_{0}, y_{0}\right)$ at which the phase exhibits a singularity and amplitude is set to zero. 

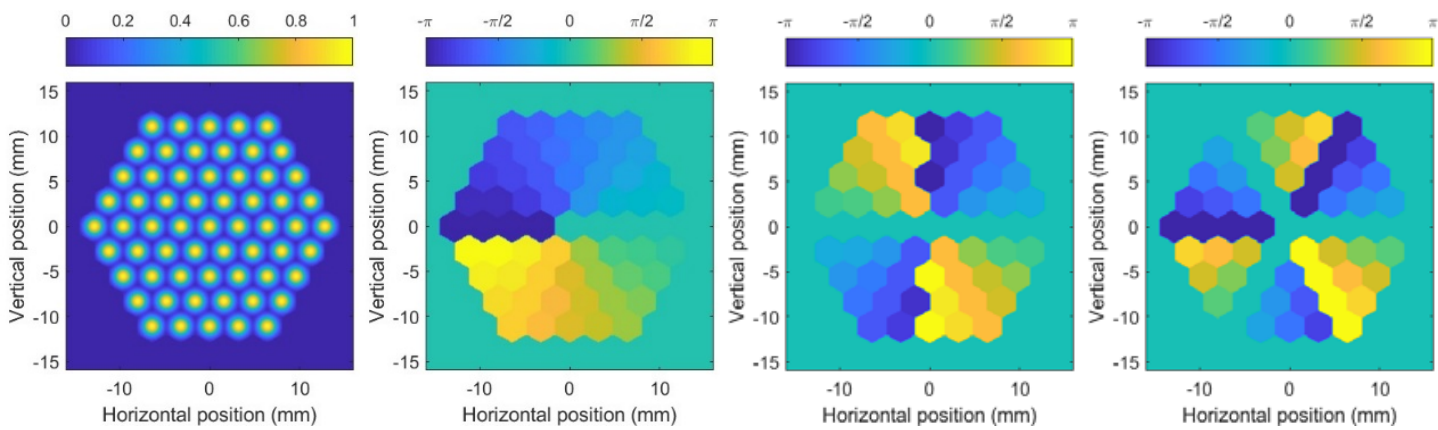

Fig. 2. Computed XCAN nearfield (left) and phase distributions for $\mathrm{l}=1 \& 2$ (center) and $\mathrm{l}=3$ (right) unwrapped over $[-\pi ; \pi]$.

Fig. 2 displays numerical simulation of XCAN nearfield (amplitude, left) and phase profiles for $l=1,2$ and 3 (second to fourth positions) corresponding far fields shown in Fig 3 (top images) where they are compared to recorded experimental results (bottom images). Both numeric and experimental far fields corresponding to no-phase shift (e.g. $l=0$ ) are displayed in left.
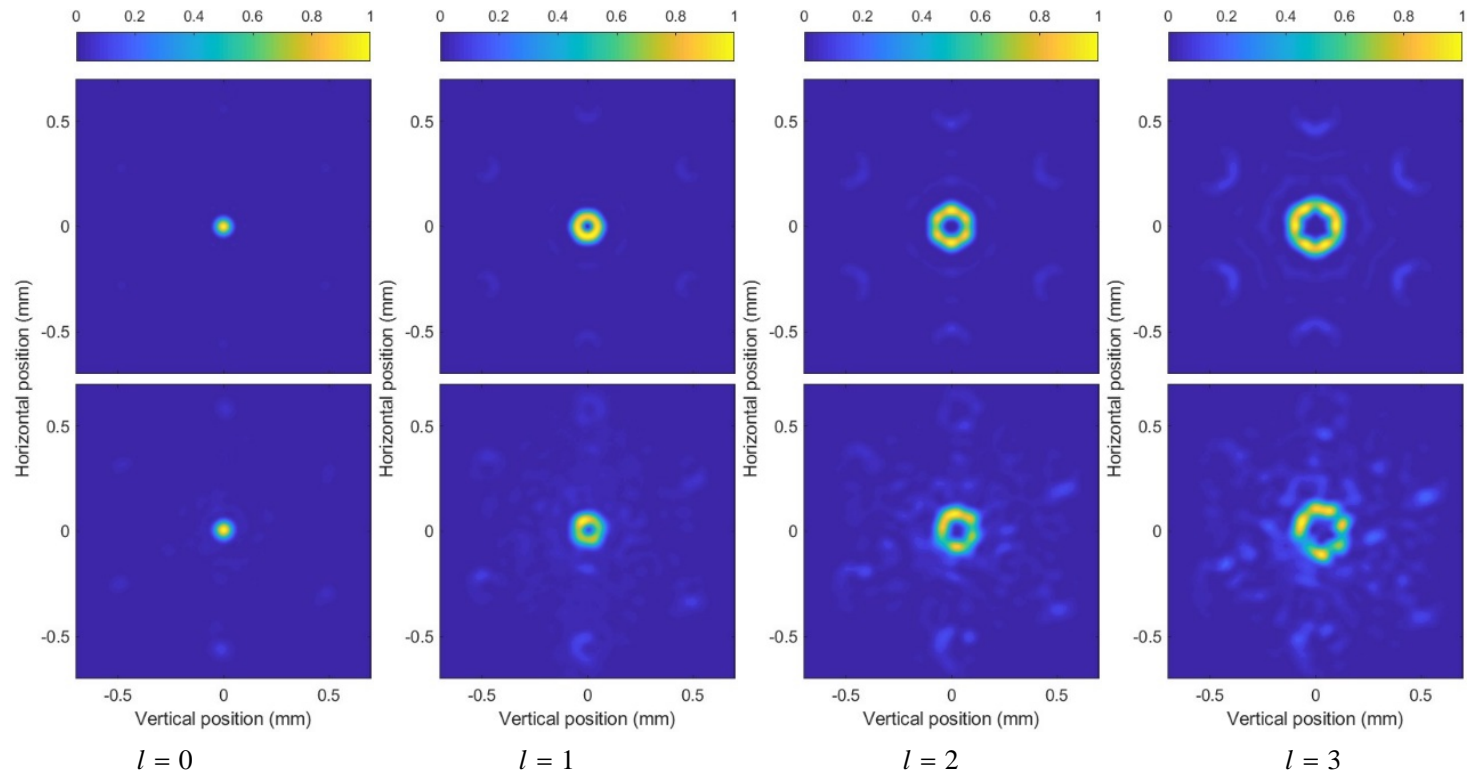

Fig. 3. Simulated (top) and experimental (bottom) far fields for different azimuthal index $l=0$ to 3 .

These results reveals a good agreement between both simulated and experimental far fields for each azimuthal index. The experimental measurements were recorded at $55 \mathrm{MHz}, 10 \mathrm{~W}$ average power. Further developments will include high average power operation (several 100 Watts), and generation of non-centrosymmetric far field distributions.

\section{References}

[1] G. Tkachenko et al., "Helicity-dependent three-dimensional optical trapping of chiral microparticles," Nat. Commun. 5 (2014).

[2] N. Liebster et al., "Laguerre-Gaussian and beamlet array as second generation laser heater profiles," Phys. Rev. Accel. Beams 21, 090701 (2018).

[2] Ryabtsev et al., "Fluid flow vorticity measurement using laser beams with orbital angular momentum", Opt. Express 24(11), 11762 (2016)

[4] A. Mock et al., "Tunable Orbital Angular Momentum Radiation from Angular-Momentum-Biased Microcavities”, Phys. Rev. Lett. $121,103901$.

[5] L.Zhu et al., "Arbitrary manipulation of spatial amplitude and phase using phase-only spatial light modulators”, Sci Rep 4, 7441 (2015)

[6] R. Lemons et al., "Programmable control of femtosecond structured light," in Conference on Lasers and Electro-Optics 2019, p. SW4E.6.

[7] A. Heilmann et al., "Coherent beam combining of seven fiber chirped-pulse amplifiers using an interfero- metric phase measurement," Opt. Express 26, 31542-31553 (2018).

[8] M. Antier, "Mesure interférométrique de phase et application à la combinaison cohérente d'un grand nombre de fibres amplificatrices », PhD thesis, https://tel.archives-ouvertes.fr/tel-01138459 (2014).

[9] R. W. Gerchberg et al., “A Practical Algorithm for the Determination of Phase from Image and Diffraction Plane Pictures,” Optik 35, 237 (1972). [10] I. Fsaifes et al., "Coherent Beam combining of 37 femtosecond fiber amplifiers", The European Conference on Lasers and Electro-Optics 2019, Munich, Germany, 23-27 June 2019, paper ca_1_6. 